УДК $330.34 ; 332.1$

ББК 65.9 (2Poc)-98

DOI 10.31554/2222-9175-2021-42-131-138

А. Б. Аугаржапова

УРОВЕНЬ И ПРИЗНАКИ РЕГИОНААЬНОЙ АЕПРЕССИВНОСТИ (на примере Республики Бурятия)

В статье затронуты вопросы отнесения регионов Российской Федерации к депрессивным вследствие усиления их неравенства по уровню социально-экономического развития. Отмечена несформированность механизмов оценки уровня депрессивности развития и набора индикаторов на региональном уровне. На примере Республики Бурятия рассмотрены базисные показатели, характеризующие депрессивный уровень. Выделены основные признаки депрессивности региона.

Ключевые слова: депрессивность, депрессивный регион, критерии оценки, региональное развитие, рост, кризисная ситуация.

D. B. Dugarzhapova

\title{
LEVEL AND SIGN OF REGIONAL DEPRESSION (the case of the Republic of Buryatia)
}

The article touches upon the issues of classifying the regions of the Russian Federation as depressive due to the increase in their inequality in terms of socio-economic development. Currently, there is a lack of a mechanism for assessing the level of developmental depression and a set of indicators at the regional level. Cnsidered basic indicators characterizing the depressive level on the example of the Republic of Buryatia. Highlighted are the main features of the region's depression.

Keywords: depression, depressed region, assessment criteria, regional development, growth, crisis situation.

$\mathbf{Q}$ озрастающие масштабы пространственной социально-экономической дифференциации вследствие протекающих социально-экономических преобразований обусловливают усиление неравенства регионов РФ по уровню социально-экономического развития. В некоторых регионах наблюдается длительное ухудшение социально-экономических показателей (снижение объемов производства, покупательской способности населения, рост безработицы, миграции и т. д.), что приводит к снижению уровня жизни населения и возникновению депрессивных регионов, в которых устанавливаются социально-экономические показатели ниже средних по стране. Для осуществления политики, направленной на стабилизацию ситуации и преодоление диспропорций развития, необходимо своевременно определить «депрессивность» территории, выявить особенности и проблемы региональной депрессивности.

В отечественных и зарубежных исследованиях существует множество критериев депрессивности территории [Гранберг 2004; Зайцева, Гранберг 2007; Зубаревич].

ДУГАРЖАПОВА Долгорма Баторовна - кандидат экономических наук, старший научный сотрудник отдела региональных экономических исследований Федерального государственного бюджетного учреждения науки Бурятский научный центр СО РАН (г. Улан-Удэ, Россия). E-mail: dolgor@mail.ru. 
В качестве базовых критериев большинством авторов принимается многократный спад производства в основных отраслях экономики территории, произошедший в течение последних 15 лет, рост бедности и безработицы, превышающей среднероссийский уровень, низкие душевые доходы, отрицательный прирост населения [Асаубаев 2006; Мансуров, Мансурова 2012; Мацкевич 2004]. Все их можно свести в определенные группы: динамика производства, уровень жизни, занятость и безработица [Елфимова, Левушкина 2012: 607].

Стагнация экономической деятельности. Безусловно, для оценки уровня развития экономики наиболее распространенным показателем является ВВП (ВРП) на душу населения. За 1998-2018 гг. по данному показателю Республика Бурятия (РБ) занимала лучшую позицию среди регионов России (РФ) в 2003 г. (41-е место), среди регионов Дальневосточного федерального округа РФ (ДФО) в 2004 г. (9-е место). В последние годы регион переместился на 75-ю позицию по РФ и 11-е место по ДФО. Несмотря на в целом положительную динамику роста ВРП на душу населения в регионе, его доля в среднедушевом объеме по РФ и ДФО снизилась в 1,5 раза. В 2018 г. его значение в 2,5 раза ниже среднероссийского (табл. 1).

Таблица 1

Валовой региональный продукт на душу населения, тыс. руб.

\begin{tabular}{|c|c|c|c|c|c|c|c|}
\hline \multirow{2}{*}{ Год } & \multirow{2}{*}{ РФ } & ДФО & \multicolumn{5}{|c|}{ Республика Бурятия } \\
\cline { 5 - 9 } & & тыс. руб. & $\begin{array}{c}\text { \% к средне- } \\
\text { душевому } \\
\text { объему по РФ }\end{array}$ & $\begin{array}{c}\text { \% к средне- } \\
\text { душевому } \\
\text { объему по ДФО }\end{array}$ & $\begin{array}{c}\text { Место } \\
\text { в РФ }\end{array}$ & $\begin{array}{c}\text { Место } \\
\text { в ДФО }\end{array}$ \\
\hline 1998 & 15,37 & 18,06 & 10,95 & 71,26 & 60,66 & 46 & 9 \\
\hline 2005 & 125,66 & 112,96 & 77,31 & 61,53 & 68,44 & 44 & 10 \\
\hline 2010 & 263,83 & 287,69 & 137,56 & 52,14 & 47,82 & 59 & 11 \\
\hline 2015 & 449,10 & 487,85 & 206,88 & 46,07 & 42,41 & 70 & 11 \\
\hline 2016 & 472,05 & 506,92 & 201,62 & 42,71 & 39,77 & 74 & 11 \\
\hline 2017 & 509,38 & 529,94 & 204,83 & 40,21 & 38,65 & 75 & 11 \\
\hline 2018 & 578,74 & 634,21 & 229,84 & 39,71 & 36,24 & 75 & 11 \\
\hline
\end{tabular}

Сост. по: [Валовой региональный продукт... (1998-2015 гг.)].

Снижение уровня среднедушевого производства ВРП Республики Бурятия обусловлено некоторым замедлением роста индексов физического объема ВРП региона относительно аналогичных индексов по России и ДФО. За последние 20 лет доля региона в суммарном ВВП страны снизилась на $0,22 \%$, а в ВРП округа - на 2,27 \% (табл. 2).

ВРП региона является одним из низких в Дальневосточном федеральном округе. Так, в частности, в 2018 г. Республика Бурятия занимала лишь 8-ю позицию по производству продукции среди субъектов ДФО с отставанием от среднеокружного более чем в 10 раз.

Анализ динамики секторов экономики за 2005-2018 гг. свидетельствует о снижении доли первичного сектора экономики на 3,6 \%, вторичного сектора - на 1,5 \% и росте третичного сектора на 5,1\% (табл. 3 ). 
Таблица 2

Валовой региональный продукт и индекс физического объема ВРП Республики Бурятия

\begin{tabular}{|c|c|c|c|c|c|c|c|c|}
\hline \multirow{2}{*}{ Год } & \multicolumn{3}{|c|}{$\begin{array}{c}\text { ИФО ВВП (ВРП) } \\
\text { к пред. году, \% }\end{array}$} & \multicolumn{3}{|c|}{ ВВП (ВРП), млн руб. } & \multirow{2}{*}{$\begin{array}{c}\text { Доля ВРП } \\
\text { РБ в ВВП } \\
\text { РФ, \% }\end{array}$} & \multirow{2}{*}{$\begin{array}{c}\text { Доля ВРП } \\
\text { РБ в ВРП } \\
\text { ДФО, \% }\end{array}$} \\
\hline & РФ & ДФО & РБ & РФ & ДФО & РБ & & \\
\hline 1998 & 93,5 & 92,1 & 94,1 & 2251977,5 & 168173,0 & 11140,0 & 0,49 & 6,62 \\
\hline 2005 & 107,6 & 104,6 & 104,8 & 18034385,2 & 970981,7 & 74912,9 & 0,42 & 7,72 \\
\hline 2010 & 104,6 & 106,3 & 103,5 & 37687768,2 & 2410988,7 & 133525,6 & 0,35 & 5,54 \\
\hline 2015 & 99,4 & 100,5 & 99,6 & 65750633,6 & 4033862,5 & 202823,4 & 0,31 & 5,03 \\
\hline 2016 & 100,8 & 99,9 & 93,5 & 69237704,4 & 4183642,3 & 198230,1 & 0,29 & 4,74 \\
\hline 2017 & 101,8 & 100,0 & 98,0 & 74798938,7 & 4363592,9 & 201614,7 & 0,27 & 4,62 \\
\hline 2018 & 102,8 & 103,5 & 104,7 & 84976724,3 & 5204116,8 & 226134,7 & 0,27 & 4,35 \\
\hline
\end{tabular}

Сост. по: [Валовой региональный продукт... 1998-2016 гг.; Регионы России... 2019].

Таблица 3

Структура ВРП в разрезе секторов экономики, \%

\begin{tabular}{|l|c|c|c|c|c|c|c|c|c|}
\hline \multirow{2}{*}{ Субъект РФ } & \multicolumn{3}{|c|}{$\begin{array}{c}\text { Сельское хозяйство } \\
\text { (первичный сектор) }\end{array}$} & \multicolumn{2}{c|}{$\begin{array}{l}\text { Промышленность } \\
\text { (вторичный сектор) }\end{array}$} & \multicolumn{3}{c|}{ Услуги } \\
\cline { 2 - 12 } & 2005 & 2015 & 2018 & 2005 & 2015 & 2018 & 2005 & 2015 & 2018 \\
\hline РФ & 18,3 & 16,6 & 17,9 & 24,2 & 23,6 & 22,5 & 57,5 & 59,8 & 59,6 \\
\hline ДФО & 23,4 & 32,8 & 35,3 & 16,4 & 12,3 & 11 & 60,2 & 54,9 & 53,7 \\
\hline $\begin{array}{l}\text { Республика } \\
\text { Бурятия }\end{array}$ & 14,1 & 10,2 & 10,5 & 15,3 & 23,6 & 13,8 & 70,6 & 66,2 & 75,7 \\
\hline $\begin{array}{l}\text { Республика } \\
\text { Саха (Якутия) }\end{array}$ & 16 & 17 & 19,4 & 8,8 & 9,4 & 7,3 & 75,2 & 73,6 & 73,3 \\
\hline $\begin{array}{l}\text { Забайкальский } \\
\text { край }\end{array}$ & 43,6 & 50,8 & 52,3 & 8,8 & 8,2 & 10 & 47,6 & 41 & 37,7 \\
\hline Камчатский край & 29 & 25,4 & 25,9 & 13,1 & 13,4 & 15,5 & 57,9 & 61,2 & 58,6 \\
\hline Приморский край & 15 & 11 & 8,4 & 13,9 & 13,1 & 12,3 & 71,1 & 75,9 & 79,3 \\
\hline Хабаровский край & 14,8 & 12,5 & 12,5 & 20,9 & 17,1 & 14,4 & 64,3 & 70,4 & 73,1 \\
\hline Амурская область & 14,7 & 24,8 & 15,1 & 12,9 & 15,7 & 17,7 & 72,4 & 59,5 & 67,2 \\
\hline $\begin{array}{l}\text { Магаданская } \\
\text { область }\end{array}$ & 32,4 & 34,6 & 42,7 & 7,1 & 12,7 & 6,5 & 60,5 & 52,7 & 50,8 \\
\hline $\begin{array}{l}\text { Сахалинская } \\
\text { область }\end{array}$ & 30,6 & 63,9 & 70,9 & 34,8 & 8,9 & 7,6 & 34,6 & 27,2 & 21,5 \\
\hline $\begin{array}{l}\text { Еврейская } \\
\text { автономная } \\
\text { область }\end{array}$ & 17,3 & 12,8 & 13,7 & 20,3 & 14,8 & 14,7 & 62,4 & 72,4 & 71,6 \\
\hline $\begin{array}{l}\text { Чукотский } \\
\text { автономный округ }\end{array}$ & 13,3 & 49,1 & 40 & 21,5 & 6 & 7,4 & 65,2 & 44,9 & 52,6 \\
\hline
\end{tabular}

Сост. по: [Регионы России... 2019]. 
Значительное превалирование сферы услуг в структуре экономики региона отражает общероссийские тенденции социально-ориентированного развития. Так, в 2018 г. в экономике региона доля сферы услуг в 7,2 раза превысила долю первичного сектора, в 5,5 раза - вторичного. В качестве основных видов экономической деятельности следует выделить оптовую и розничную торговлю $(12,6 \%)$, транспортировку и хранение (10,8 \%), обрабатывающие производства $(9,9 \%)$.

Данное положение отражает и анализ динамики объемов производства в основных отраслях экономики региона. За последние 15 лет наблюдается снижение удельного веса региона в объеме отгруженной продукции ДФО на 4 \%, в валовой продукции сельского хозяйства - на 3,9 \%, обороте розничной торговли - на 2,2 \% (табл. 4).

Таблица 4

Динамика объемов производства в основных отраслях экономики РБ

за 2005-2019 гг., млрд руб.

\begin{tabular}{|l|c|c|c|c|c|c|c|c|}
\hline \multirow{2}{*}{\multicolumn{1}{|c|}{ Показатель }} & \multicolumn{2}{|c|}{2005} & \multicolumn{2}{c|}{2010} & \multicolumn{2}{c|}{2015} & \multicolumn{2}{c|}{2019} \\
\cline { 2 - 9 } & ДФО & РБ & ДФО & РБ & ДФО & РБ & ДФО & РБ \\
\hline $\begin{array}{l}\text { Объем отгруженной } \\
\text { продукции } \\
\text { промышленности }\end{array}$ & 495,2 & 37,8 & 1340,1 & 64,9 & 2665,8 & 131,2 & 3910,1 & 139,4 \\
\hline $\begin{array}{l}\text { Вал. продукция } \\
\text { с/хозяйства }\end{array}$ & 63,8 & 8,0 & 114,2 & 10,2 & 180,5 & 16,0 & 192,7 & 16,5 \\
\hline $\begin{array}{l}\text { Объем работ по } \\
\text { деятельности } \\
\text { «строительство» }\end{array}$ & 155,1 & 5,0 & 373,4 & 15,9 & 434,6 & 20,7 & 609,9 & 27,8 \\
\hline $\begin{array}{l}\text { Объем платных } \\
\text { услуг населению }\end{array}$ & 151,7 & 8,9 & 344,0 & 20,7 & 553,8 & 41,9 & 666,6 & 46,0 \\
\hline $\begin{array}{l}\text { Оборот розничной } \\
\text { торговли }\end{array}$ & 287,6 & 35,3 & 657,1 & 85,4 & 1188,6 & 162,6 & 1878,5 & 189,1 \\
\hline
\end{tabular}

Сост. по: [Регионы России... 2019].

Выявленные негативные тенденции свидетельствуют о вытеснении из региональной структуры ВРП реального и сельскохозяйственного производства, что негативно отражается на возможности диверсификации региональной экономики в пользу других отраслей.

Немаловажным показателем, определяющим темп и качество развития региона, является бюджет. За 2005-2019 гг. Республика Бурятия, несмотря на рост налоговых доходов (в 4,9 раза) и безвозмездных поступлений (в 5,9 раза), является дотационным регионом (табл. 5).

Проблемой доходной базы бюджета является отсутствие в регионе крупных компаний-налогоплательщиков. Например, в 2019 г. доля налога на прибыль организаций составила 28,3 \% всех доходов, в то время как поступления налога на доходы физических лиц были почти в два раза выше и составили 53,9 \%. Таким образом, налог на доходы физических лиц (прежде всего на заработную плату) является важнейшим источником пополнения бюджета. В структуре расходов региона преобладает социальная направленность. На финансовое обеспечение 
социальной политики, образования, здравоохранения, культуры, физкультуры и спорта в течение 2019 г. было направлено 57214,3 млн руб., что выше аналогичного уровня 2018 г. на $25 \%$.

Таблица 5

Показатели консолидированного бюджета Республики Бурятия, млрд руб.

\begin{tabular}{|l|c|c|c|c|c|c|}
\hline \multicolumn{1}{|r|}{ Год } & 2005 & 2010 & 2015 & 2017 & 2018 & 2019 \\
\hline Доходы, всего & 15,6 & 39,2 & 52,8 & 56,6 & 64,8 & 80,1 \\
\hline $\begin{array}{l}\text { В т. ч.: } \\
\text { налог на прибыль организаций }\end{array}$ & 1,4 & 3,5 & 7,4 & 5,3 & 6,9 & 8,0 \\
\hline налог на доходы физических лиц & 3,3 & 8,0 & 11,4 & 12,9 & 14,4 & 15,3 \\
\hline налог на имущество & 1,0 & 1,7 & 4,2 & 4,5 & 5,4 & 5,0 \\
\hline Безвозмездные поступления & 7,3 & 21,2 & 23,8 & 27,1 & 30,7 & 43,0 \\
\hline Расходы, всего & 15,8 & 40,8 & 54,1 & 59,3 & 65,2 & 80,6 \\
\hline $\begin{array}{l}\text { Из них на: } \\
\text { общегосударственные вопросы }\end{array}$ & 1,4 & 3,7 & 4,0 & 4,4 & 5,1 & 5,3 \\
\hline национальную экономику & 1,1 & 4,8 & 8,0 & 9,6 & 8,6 & 11,4 \\
\hline жилищно-коммунальное хозяйство & 1,2 & 3,0 & 4,0 & 3,4 & 2,9 & 4,1 \\
\hline $\begin{array}{l}\text { социально-культурные } \\
\text { мероприятия }\end{array}$ & 11,4 & 25,8 & 36,1 & 40,2 & 45,8 & 57,2 \\
\hline Профицит/дефицит (-) & $-0,3$ & $-1,6$ & $-1,2$ & $-2,7$ & $-0,4$ & $-0,5$ \\
\hline
\end{tabular}

Сост. по: [Регионы России... 2019].

Уровень жизни. Основным показателем, напрямую зависящим от развития экономической сферы и характеризующим степень депрессивности региона, является уровень благосостояния населения по доходам.

По величине среднедушевых доходов и среднемесячной заработной платы Бурятия занимает последнее место среди регионов ДФО. По доходам регион отстает от среднероссийских и средних по округу значений соответственно в 1,4 и в 1,5 раза, по заработной плате - в 1,2 и 1,4 раза соответственно. За 2005-2019 гг. уровень бедности населения снизился на 12,5 \%, тем не менее регион занимает 9-ю позицию в рейтинге субъектов ДФО (табл. 6). Отметим, что наименьшее значение численности населения с доходами ниже прожиточного уровня было достигнуто в 2013 г. За IV квартал 2019 г. величина прожиточного минимума в среднем по региону составила 11274, а для трудоспособного населения - 11726 руб. [Величина...].

Невысокий уровень жизни сопровождается значительной дифференциацией доходов. 43,6 \% всех официальных денежных доходов республики сосредоточены в руках населения с наивысшими доходами Соотношение $20 \%$ наиболее обеспеченного населения региона и 20 \% наименее обеспеченного в 2019 г. составило 11,5 раза (в России - 15,6 раза). 
Таблица 6

Динамика доходов населения Республики Бурятия

\begin{tabular}{|l|c|c|c|c|c|c|}
\hline \multicolumn{1}{|c|}{ Год } & 2005 & 2010 & 2015 & 2017 & 2018 & 2019 \\
\hline $\begin{array}{l}\text { Преказатель } \\
\text { доходы, руб. в месяц }\end{array}$ & 6027 & 14271 & 23858 & 23860 & 24081 & 25268 \\
\hline $\begin{array}{l}\text { Среднемесячная } \\
\text { номинальная начисленная } \\
\text { заработная плата, руб. }\end{array}$ & 7651 & 18000 & 28386 & 32237 & 36047 & 39115 \\
\hline $\begin{array}{l}\text { Численность населения } \\
\text { с доходами ниже } \\
\text { прожиточного уровня, \% }\end{array}$ & 32,6 & 19,2 & 18,9 & 19,0 & 19,1 & 20,1 \\
\hline
\end{tabular}

Сост. по: [Регионы России... 2019].

Занятость и безработица. В 2019 г. уровень экономической активности населения Республики Бурятия $(57,4 \%)$ ниже, чем в среднем по стране $(62,3 \%)$ и ДФО (63,9 \%). Для сельской местности этот показатель равен 51,1 \%, что на 5,9 \% ниже, чем по стране, и на 5,5 \% - по округу в целом; для городского населения показатель составил 61,5 \% (ниже значений по стране и округу на 3,5 \% и 4,0 \% соответственно). Наибольшая численность занятых наблюдается в отраслях промышленности (16\%), социальной сферы $(17,3 \%)$, торговли и других видов услуг $(43,9 \%)$.

Уровень безработицы $(9,2 \%)$ в регионе в 2 раза выше среднего по России и в 1,5 раза - по ДФО. Из всех безработных 25,9 \% имеют высшее образование, 37,6 \% - среднее профессиональное и 36,6 \% - ниже среднего общего. Доля безработной молодежи (20-29 лет) несколько ниже, чем в среднем по ДФО (27,6 \% и 33,0 \% соответственно), зато очень высока доля безработных в возрасте 30-39 лет (30 \%, в ДФО - 25,6 \%). Данные показатели свидетельствуют о наличии проблем качества трудовых ресурсов, структурных дисбалансов спроса и предложения на рынке труда, что обусловливает и углубляет депрессивное состояние экономики региона.

Полученные результаты позволяют сделать вывод, что наряду с положительными сдвигами существуют и негативные тенденции по ряду экономических показателей, вызывающие определенную остроту ситуации и социальную напряженность среди населения, что, в свою очередь, отражает степень депрессивности региона. На основе проведенного анализа представляется возможным выделить ряд признаков депрессивности Республики Бурятия:

- ограниченность использования ресурсных возможностей и низкая степень адаптации отраслей экономики региона к условиям рынка, обусловленная недостаточным развитием социальной, производственной и рыночной инфраструктуры;

- низкий уровень доходов и общий уровень жизни населения;

- значительная дифференциация благосостояния населения наряду с достаточно высоким уровнем бедности в регионе;

- наличие проблем качества трудовых ресурсов и структурных дисбалансов спроса и предложения на рынке труда.

В целом выделенные признаки депрессивности прежде всего свидетельствуют о необходимости оперативного вмешательства органов управления с целью изменения опасных тенденций. 


\section{Источник и литература}

Регионы России. Социально-экономические показатели. 2019: стат. сб. / Росстат. M., 2019. - 1204 c.

Асаубаев $A$. К. Критерии и методы оценки депрессивности территориальных ситуаций / А. К. Асаубаев // Труды ИСА РАН. - 2006. - Т. 22. - С. 251-260.

Валовой региональный продукт в текущих основных ценах на душу населения (19982015 гг.) [Электронный ресурс]. - Режим доступа: https://rosstat.gov.ru/accounts (дата обращения: 15.02.2021).

Валовой региональный продукт по субъектам Российской Федерации в 1998-2016 гг. [Электронный ресурс]. - Режим доступа: https://rosstat.gov.ru/accounts (дата обращения: 15.02.2021).

Величина прожиточного минимума в целом по России и по субъектам Российской Федерации [Электронный ресурс]. - Режим доступа: https://rosstat.gov.ru/folder/13723\# (дата обращения: 22.02.2021).

Гранберг А. Г. Экономическое пространство России: вечные проблемы, трансформационные процессы, поиск стратегий / А. Г. Гранберг // Экономическое возрождение России. - 2004. - № 1. - С. 16-22.

Елфимова Ю. М. Земельный ресурс как один из основных факторов осуществления сельского предпринимательства / Ю. М. Елфимова, С. В. Левушкина // Политематический сетевой электронный научный журнал Кубанского государственного аграрного университета. - 2012. - № 83. - С. 606-616.

Зайцева Ю. С. Межрегиональные экономические сопоставления: макроиндикаторы и комплексные оценки / Ю. С. Зайцева, А. Г. Гранберг // Вестник Российского гуманитарного научного фонда. - 2007. - № 1. - С. 41-57.

Зубаревич Н. В. Мониторинг кризиса и посткризисного развития регионов России [Электронный ресурс] / Н. В. Зубаревич. - Режим доступа: http://www.socpol.ru/atlas/ overviews/social_sphere/kris.shtml\#no01.

Мансуров П. М. Критерии оценки депрессивности региона / П. М. Мансуров, Г. И. Мансурова // Национальные интересы: приоритеты и безопасность. - 2012. - № 25. - С. 44-49.

Мацкевич T. Н. Проблемы социально-экономического развития региона / Т. Н. Мацкевич. - Ставрополь: Аргуз, 2004. - 120 с.

\section{References}

Regiony Rossii. Social'no-ekonomicheskie pokazateli. 2019: stat. sb. / Rosstat. - M., 2019. $-1204 \mathrm{~s}$.

Asaubaev A. K. Kriterii i metody ocenki depressivnosti territorial'nyh situacij / A. K. Asaubaev // Trudy ISA RAN. - 2006. - T. 22. - S. 251-260.

Valovoj regional'nyj produkt $\mathrm{v}$ tekushchih osnovnyh cenah na dushu naseleniya (1998-2015 gg.) [Elektronnyj resurs]. - Rezhim dostupa: https://rosstat.gov.ru/accounts (data obrashcheniya: 15.02.2021).

Valovoj regional'nyj produkt po sub"ektam Rossijskoj Federacii v 1998-2016 gg. [Elektronnyj resurs]. - Rezhim dostupa: https://rosstat.gov.ru/accounts (data obrashcheniya: 15.02.2021).

Velichina prozhitochnogo minimuma v celom po Rossii i po sub"ektam Rossijskoj Federacii [Elektronnyj resurs]. - Rezhim dostupa: https://rosstat.gov.ru/folder/13723\# (data obrashcheniya: 22.02.2021).

Granberg A. G. Ekonomicheskoe prostranstvo Rossii: vechnye problemy, transformacionnye processy, poisk strategij / A. G. Granberg // Ekonomicheskoe vozrozhdenie Rossii. - 2004. № 1. - S. 16-22.

Elfimova Yu. M. Zemel'nyj resurs kak odin iz osnovnyh faktorov osushchestvleniya sel'skogo predprinimatel'stva / Yu. M. Elfimova, S. V. Levushkina // Politematicheskij setevoj elektronnyj nauchnyj zhurnal Kubanskogo gosudarstvennogo agrarnogo universiteta. - 2012. - № 83. S. 606-616. 
Zajceva Yu. S. Mezhregional'nye ekonomicheskie sopostavleniya: makroindikatory i kompleksnye ocenki / Yu. S. Zajceva, A. G. Granberg // Vestnik Rossijskogo gumanitarnogo nauchnogo fonda. - 2007. - № 1. - S. 41-57.

Zubarevich N. V. Monitoring krizisa i postkrizisnogo razvitiya regionov Rossii [Elektronnyj resurs] / N. V. Zubarevich. - Rezhim dostupa: http://www.socpol.ru/atlas/overviews/social_sphere/ kris.shtml\#no01.

Mansurov P. M. Kriterii ocenki depressivnosti regiona / P. M. Mansurov, G. I. Mansurova // Nacional'nye interesy: prioritety i bezopasnost'. - 2012. - № 25. - S. 44-49.

Mackevich T. N. Problemy social'no-ekonomicheskogo razvitiya regiona / T. N. Mackevich. - Stavropol': Arguz, 2004. - 120 s. 